\title{
Ingeniería tisular y medicina regenerativa en cirugía pediátrica*
}

\author{
Dr. MATÍAS GARRIDO F. ${ }^{1}$
}

1 Residente Cirugía Pediátrica. Universidad de Valparaíso. Valparaíso, Chile.

\section{Tissue engineering and regenerative medicine in pediatric surgery}

\section{Introducción}

Las fuentes actuales de tejidos para uso reconstructivo están asociadas a numerosas complicaciones. Frente a estos problemas, la Ingeniería Tisular y la Medicina Regenerativa surgen como las disciplinas que reúnen los conocimientos de la biología celular y las ciencias de la ingeniería aplicada a la formación de tejidos y órganos artificiales para uso clínico. En el campo de la cirugía pediátrica, muchos investigadores han creado tejidos artificiales para enfermedades de la infancia. En algunos casos, hay sólo conocimiento y capacidad de generar determinados tejidos y estructuras, por ejemplo, los riñones y los pulmones. En otras situaciones, han sido regenerados por completo algunos órganos en modelos animales, como el tracto gastrointestinal. En otras especialidades, los avances de la Ingeniería Tisular y Medicina Regenerativa se utilizan hoy en día en niños enfermos, sobre todo en áreas como la cirugía cardíaca, urología y cirugía plástica. En el futuro se deben resolver aspectos relacionados con la ética, las ciencias básicas, la economía y la clínica, para el progreso de estas ciencias emergentes.

Actualmente la medicina cuenta con tres grandes fuentes de tejidos para uso reconstructivo ${ }^{1}$. En primer lugar tenemos el tejido sintético (protésico), que por su naturaleza no posee potencialidad para crecer, remodelarse o ser reparado. El otro origen es el tejido autólogo, proveniente del mismo individuo; este, sin embargo, cuenta con las limitaciones de falta de suministro suficiente para cubrir la mayoría de las necesidades, y de potencial transformación maligna, por ejemplo, al sustituir tejido urinario por digestivo, cuyo epitelio no está especializado en hacer frente a las toxinas de la orina, produciendo metaplasia y posteriores cambios neoplásicos. Otra opción la constituyen los trasplantes, los cuales pueden corresponder a aloinjertos (entre sujetos de la misma especie), o xenoijertos, cuando son entre diferentes especies (en el caso de los injertos de piel de cerdo en pacientes quemados). En este caso particular estamos frente a la denominada "crisis del trasplante", especialmente en pediatría. Sumado a la escasez de donantes por asuntos anatómicos y sociales, existe una alta mortalidad durante la lista de espera. Además del rechazo inmune que se observa, constituye un grave problema el efecto a largo plazo de la terapia inmunosupresora. Frente a estas necesidades la Ingeniería Tisular emerge como una alternativa futurística que ha comenzado a tomar vida, desembarcando desde el laboratorio al paciente, logrando en algunos casos la solución frente a problemas de salud, dando origen a la Medicina Regenerativa. En la etapa infantil, producto de la adaptación rápida y óptima en comparación a los adultos, sumado a la necesidad de sustitutos que crezcan con el enfermo, y el seguimiento a largo

*Recibido el 24 de julio de 2011 y aceptado para publicación el 18 de agosto de 2011.

Correspondencia: Dr. Matías Garrido F.

Montecasino \#941, Maipú, Santiago, Chile.

matias.raul@gmail.com 
plazo que brinda la especialidad, es posible advertir que parte del futuro de la cirugía pediátrica está en estas revolucionarias disciplinas ${ }^{2-4}$.

La historia de estas ciencias tiene entre sus antepasados a Charles A. Lindbergh y Alexis Carrel, quienes en 1938 publicaron el libro The culture of organs, dando inicio al cultivo tisular en el laboratorio. Sin embargo, fue a finales de la década de 1980 cuando se acuña el término de Ingeniería Tisular, el cual se define como la aplicación de los principios y métodos de las ciencias de la ingeniería y de la vida hacia el entendimiento de las relaciones estructurafunción en condiciones normales o patológicas. Esta tecnología multidisciplinaria ha sido usada para desarrollar sustitutos biológicos para reparar o regenerar tejidos y órganos funcionales ${ }^{5}$.

Los tres pilares que constituyen a la Ingeniería Tisular son la biología celular, las ciencias de la ingeniería y la medicina clínica ${ }^{4}$. Desde estas disciplinas se desprenden los desafíos a vencer: la identificación de tejidos y órganos capaces de ser reemplazados; la obtención de células madres tanto embrionarias como adultas; el entendimiento de la señalización celular; llevar a cabo vascularización tanto in vitro como in vivo; la construcción de matrices; y la formación de biorreactores. Estas dos últimas situaciones implican altamente el desarrollo de tecnología. Las matrices son estructuras donde irán insertos los tejidos, constituidos principalmente por polímeros como el ácido poliglicoico (PGA). Deben permitir la interacción con el cultivo, promover la adhesión celular y el depósito de matriz extracelular, transporte de gases y nutrientes, y su degradación debe ser controlada y no generar productos tóxicos, a fin de minimizar la respuesta inflamatoria in vivo ${ }^{6}$. Los biorreactores son sistemas que proveen un ambiente controlado para promocionar el crecimiento y la organización celular en las matrices. Deben ser componentes dinámicos en los cuales exista transferencia de masa y que cuenten con flujo pulsátil, a fin de emular las condiciones más fisiológicas posibles? ${ }^{7}$. En caso de no contar con el medio suficiente, el mismo cuerpo es capaz de ser usado como biorreactor.

A continuación revisaremos cada uno de los tejidos, órganos y sistemas cuyo potencial de regeneración ha sido estudiado, los modelos experimentales y su eventual desarrollo clínico en las distintas áreas de la cirugía pediátrica.

\section{Cardiocirugía}

Respecto a la edad pediátrica, adquiere vital importancia el desarrollo de la Ingeniería Tisular para hacer frente a las cardiopatías congénitas. Actualmente la Medicina Regenerativa ha sido probada en las siguientes condiciones que atañen a la cardiocirugía pediátrica: válvulas, parches cardiovasculares y conductos vasculares.

Una problemática relevante es la patología de la válvula pulmonar, la cual puede ser afectada en la hipoplasia del tracto de salida del ventrículo derecho, tetralogía de Fallot, el tronco arterioso o la atresia pulmonar. Actualmente los tratamientos incluyen válvulas protésicas, bioprotésicas y homoinjertos. Sin embargo estas opciones poseen complicaciones tales como tendencia a la infección, trombosis y calcificación, lo cual conlleva a someter a un paciente a varias intervenciones durante su vida. Es así como se ha desarrollado una válvula autóloga mediante Ingeniería Tisular en pacientes adultos portadores de cardiopatías congénitas ${ }^{8}$. En adolescentes de 11 y 13 años fue probada una válvula pulmonar desarrollada por Ingeniería Tisular que logró adaptarse a los cambios producto del crecimiento de estos pacientes ${ }^{9}$.

La reparación de alteraciones cardíacas como hipoplasias, defectos septales o tetralogía de Fallot deben incluir parches cardiovasculares. Actualmente se cuenta con pericardio autólogo, pericardio bovino, polyester y Gore Tex (politetrafluoroetileno). Sin embargo, estos materiales no pueden crecer ni remodelarse, y tienen riesgo de infección y formación aneurismática. Después de pruebas en modelos experimentales, ya es una realidad el uso de parches creados por Ingeniería Tisular en cirugía cardiovascular pediátrica ${ }^{10}$.

Frente a determinadas cardiopatías congénitas como atresia pulmonar, tetralogía de Fallot, transposición de grandes vasos, tronco arterioso y otros defectos complejos, la cirugía logra solucionar problemas mediante la implantación de conductos para restablecer la continuidad anatómica. Para hacer frente a los problemas ocasionados por sustitutos como Dacron (polietileno tereftalato) o Gore Tex, tales como calcificación y obstrucción, se han desarrollado soluciones mediante Ingeniería Tisular. En una paciente de cuatro años de edad se reemplazó una arteria pulmonar creada mediante miofibroblastos derivados de su vena safena ${ }^{11}$. Además existe un ensayo clínico aplicándose en Japón donde se han implantado autoinjertos vasculares desarrollados por Ingeniería Tisular para tratar patologías que cursan con ventrículo único como atresia tricuspídea, atresia pulmonar o síndrome del corazón izquierdo hipoplásico ${ }^{12}$.

A nivel microvascular se busca formar vasos sanguíneos para lograr soluciones a problemas puntuales o para mejorar la perfusión de otros tejidos y órganos construidos artificialmente. Tras la obtención de células endoteliales para el revestimiento, la búsqueda actual apunta a producir matrices que permitan el desarrollo de constructos vasculares ${ }^{13}$. 


\section{Tráquea y pulmón}

La tráquea es sustrato de patología quirúrgica infantil, tanto en estenosis y atresias traqueales, como en fístulas tráqueo-esofágicas. A la fecha se han desarrollado dos injertos traqueales realizados mediante Ingeniería Tisular Fetal, uno con condrocitos embrionarios y el otro con amniocitos mesenquimáticos, ambos con buenos resultados en modelos experimentales $^{14}$.

Frente a insuficiencia respiratoria en población pediátrica, la Medicina Regenerativa representa una opción mediante el desarrollo de tejido pulmonar. Pero al igual que sucede con el hígado, al tratarse de grandes órganos con extensa vascularización, se hace muy difícil su reproducción en este momento. El estado del arte en Ingeniería Tisular pulmonar está en relación con el desarrollo de matrices que emulen los alveolos y la barrera alveolo-capilar. Se ha reportado la existencia de células madre embrionarias presentes en el pulmón, las cuales son capaces de llevar a cabo la reparación tisular tras insultos que afectan a las vías respiratorias. Estas células colocadas en una interfase aire-agua desarrollan un epitelio altamente diferenciado que incluye células basales, ciliadas y secretoras ${ }^{15,16}$. Esta capacidad se tiene en cuenta para desarrollar en algún momento tejido pulmonar funcional mediante Ingeniería Tisular.

\section{Pared torácica y diafragma}

Diferentes patologías afectan a la pared torácica, tales como ectopia cordis, la pentalogía de Cantrell, el síndrome de Poland o algunos tumores. Es por ello que se ha reconstruido la pared torácica en animales de laboratorio por medio de condrocitos fetales, con buenos resultados experimentales ${ }^{17}$.

Respecto de la patología del diafragma, en pacientes con hernia diafragmática congénita existe una alta tasa de recurrencias al usar materiales protésicos. Por ello se creó en un modelo animal mediante mioblastos fetales un reemplazo de diafragma, el cual no presentó complicaciones posteriores a su inserción, como lo son las recurrencias ${ }^{18}$.

\section{Tubo Digestivo}

A nivel del tubo digestivo la Medicina Regenerativa ha avanzado en tres frentes: esófago, intestino y el esfínter anal interno. En el caso del esófago, el esfuerzo está puesto puntualmente en solucionar las atresias esofágicas "long gap", que corresponden a aquellas atresias donde no puede realizarse anastomosis primaria. La Ingeniería Tisular aparece como una opción ante la necesidad de contar con un reemplazo esofágico. Se ha logrado en un modelo ovino reconstruir un segmento esofágico mediante una biopsia de células epiteliales esofágicas que se siembran en láminas de colágeno previamente cubiertas con fibroblastos. Luego se coloca esta matriz en un stent a fin de obtener conformación tubular y se implanta usando material de sutura absorbible al omento, que hace de biorreactor. Posteriormente se retira desde el omento y se remueve el stent, obteniendo finalmente el esófago con su configuración tubular ${ }^{19}$.

El síndrome de intestino corto representa un grave problema de salud a cualquier edad. En pediatría puede ser causado por patologías como atresias intestinales, aganglionosis extensa en la enfermedad de Hirschsprung, gastrosquisis, intestino corto congénito, peritonitis meconial, vólvulo intestinal, enterocolitis necrotizante, trauma abdominal, enfermedad de Crohn, enteritis actínica o enfermedad vascular isquémica mesentérica. La formación de un neointestino se vislumbra como una alternativa emergente contra el alto impacto producido por este síndrome, además de representar una opción ante el trasplante intestinal. Es por ello que mediante Ingeniería Tisular los esfuerzos están puestos en lograr el desarrollo de un órgano tubular con peristalsis, con una mucosa que digiera y absorba nutrientes. Se han creado varios modelos animales aprovechando la ventaja de que el tejido epitelial intestinal es el con más rápida proliferación del cuerpo. En distintos laboratorios del mundo se están desarrollando organoides experimentales que sean capaces de llevar a cabo las propiedades fisiológicas del intestino ${ }^{20}$.

Otro problema importante que atañe a los cirujanos pediatras es la disfunción del esfínter anal interno, en donde los pacientes cursan con incontinencia fecal. Para tratar esta situación se ha diseñado un modelo murino en el cual se extrajeron células musculares lisas y bajo una matriz los científicos produjeron un esfínter con propiedades similares a su par biológico ${ }^{21}$.

\section{Hígado, páncreas y bazo}

En la patología quirúrgica pediátrica, el hígado es un órgano que puede verse afectado en la atresia de vías biliares, entidad en la que muchos pacientes terminan por necesitar un trasplante de hígado, por ello la necesidad de contar con sustitutos hepáticos óptimos. Sin embargo, este es un órgano complejo que ha demostrado las limitaciones de la Ingeniería Tisular y la tecnología actual por su elevado metabolismo, asociado a un gran número de células que 
se necesitan para cumplir sus funciones, y debido a su exquisita anatomía que ha impedido la construcción de un árbol biliar apropiado ${ }^{22}$. Pero se han creado máquinas que utilizan Ingeniería Tisular para proveer un hígado artificial similar a los dispositivos de diálisis renal, utilizando hepatocitos porcinos. Mientras tanto se desarrollan biorreactores asociados a matrices estructuradas para lograr una perfusión adecuada en los modelos experimentales, entregándonos una versión moderna del mito de Prometeo $^{23}$.

Ante la amenaza de la Diabetes Mellitus 1, se ha creado un linaje de células $\beta$ humanas inmortalizadas mediante infección por retrovirus que no pierden su capacidad secretora. Estos cultivos son capaces de responder a altos niveles de glicemia con secreción de insulina ${ }^{24}$. El desafío actual es lograr un tejido encapsulado que se mantenga sin provocar inflamación no-específica, para que no reciba el ataque autoinmune.

La esplenectomía constituye una alternativa terapéutica frente a ciertas enfermedades hematológicas, sin embargo, la remoción del bazo deja sin protección frente agentes encapsulados como Streptococcus pneumoniae. Por ello, cuando es necesario resecar todo el tejido lienal, aparece como alternativa la regeneración esplénica mediante Ingeniería Tisular. En ratones se comparó la respuesta frente a infección por Streptococcus pneumoniae entre sujetos sanos, esplenectomizados, y con bazo regenerado. El resultado fue favorable para este último grupo, ya que lograron sobrevida similar a aquellos sanos, en comparación a los sujetos con el bazo resecado ${ }^{25}$.

\section{Urología pediátrica}

En el campo de la urología es donde la Ingeniería Tisular y la Medicina Regenerativa han conseguido más resultados, sobretodo en la población infantil. Por ejemplo, en la patología vesical pediátrica, donde enfermedades que requieren de ampliación de la vejiga urinaria tales como las valvas de uretra posterior, extrofia vesical, epispadias y vejigas neurogénicas, se han visto favorecidas con los nuevos avances. Dejando atrás las complicaciones asociadas a prótesis u otros tejidos, como ampliaciones intestinales, la realización de neovejiga en una matriz de submucosa de intestino delgado ha logrado cumplir los objetivos propuestos, obteniéndose vejigas con adecuada complacencia ${ }^{26}$.

También es el caso de la patología del desarrollo uretral como en las hipospadias, donde la sustitución por prótesis y otros tejidos tienen sus desventajas, el desarrollo de neouretra ya pasó la prueba en animales, estando actualmente en etapa de estudios clínicos en pacientes pediátricos. Situación similar se ha producido en la formación de uréteres mediante Ingeniería Tisular, donde se han logrado producir al mezclar urotelio con músculo liso ${ }^{27}$. El tratamiento del reflujo vésico-ureteral también se ha visto favorecido con la Medicina Regenerativa. Esta patología se produce principalmente por un déficit congénito en el músculo longitudinal de la submucosa del uréter distal, conduciendo un flujo anormal de orina desde la vejiga al sistema superior. Desde 1974 se han realizado terapias inyectables con productos exógenos a fin de corregir esta deficiencia. Sin embargo, estas sustancias poseen algunos efectos indeseados como migración, formación de granulomas y pérdida de volumen, situaciones que conllevan a constantes intervenciones. Mediante el desarrollo de Ingeniería Tisular se creó una suspensión condrocito-alginato que deja atrás los inconvenientes de las otras sustancias antes inyectadas ${ }^{28}$.

Los tejidos genitales son objetivo de la Medicina Regenerativa. Para paliar ciertas patologías pediátricas, como ambigüedad sexual o hipospadias severas, se han producido cuerpos cavernosos mediante Ingeniería Tisular para formar un neopene ${ }^{29}$. Este aporte también ha respondido a las necesidades de los pacientes adultos. En el caso del sexo femenino, en conejas, se creó un modelo de neovagina, en el que se realizó un trasplante autólogo de células epiteliales y musculares sobre una matriz tubular, originando un tejido vaginal que responde con contracciones de manera similar a la vagina in vivo ${ }^{30}$.

En el campo de la nefrourología pediátrica, el desafío que viene es la formación de un riñón mediante estas disciplinas, a raíz de la observación de que células renales pueden regenerarse tras injurias, a partir de células madres mesenquimales extraíbles de la médula ósea madura. De momento se han podido regenerar túbulos renales de manera experimental ${ }^{31}$.

\section{Traumatología y ortopedia infantil}

En esta área la investigación está dirigida principalmente a la patología de adultos, pero sus resultados son extrapolables a la edad pediátrica. Ejemplo de ello son los defectos ortopédicos congénitos, los errores del metabolismo óseo y los traumatismos. El mundo ya ha sido testigo de la regeneración de cartílago auricular y hueso mediante Ingeniería Tisular $^{32,33}$.

\section{Cirugía plástica}

En cirugía plástica pediátrica, la Medicina Regenerativa actualmente apunta a la solución de problemas tales como la craneosinostosis, la fisura 
labio-palatina, la microtia, quemaduras, trauma y nevus gigantes congénitos ${ }^{34}$. Actualmente existen bastantes avances para hacer frente a estos problemas, siendo una arena oportuna para capitalizar los logros de estas ciencias. Es un hecho el desarrollo de productos comerciales de piel generada por Ingeniería Tisular ${ }^{35,36}$. No obstante, hoy se quiere ir más allá y se busca construir sustitutos dérmicos con anexos incluidos mediante el uso de células madre ${ }^{37}$. Además fuimos escépticos testigos de la revolución de la Medicina Regenerativa y la Ingeniería Tisular en 1997 al ver la oreja insertada en el dorso de un ratón de laboratorio ${ }^{38}$. Sin embargo, la cirugía craneofacial aún presenta importantes limitaciones. La falta de tejido óseo de las malformaciones también implica ausencia de estructuras relacionadas como músculo, cartílago y mucosas ${ }^{39}$. La cavidad oral es de por si un sitio contaminado, haciendo más difícil llevar a cabo los procesos cicatriciales. Por ende a futuro debe alcanzarse un conocimiento adecuado en materias como adhesión celular, factores de crecimiento, control de la morfología ósea regenerada y el diseño de matrices apropiadas.

\section{Conclusión}

El futuro de la Ingeniería Tisular y la Medicina Regenerativa posee una enorme cantidad de desafíos: surgen aspectos éticos respecto de su aplicación en la edad pediátrica, así como la obtención de cierto grupo de células madre; además es necesario aumentar el conocimiento de las ciencias afines a ambas disciplinas, debe controlarse la tumorogénesis en algunos tejidos producidos de células con mucha potencialidad y alta tasa de división celular; es necesario atraer a la industria para reducir los altos costos asociados, mediante la comercialización de los productos finales; es menester seguir produciendo modelos animales y realizar ensayos clínicos controlados en humanos cuando se han logrado órganos efectivos ${ }^{40}$. De este modo estas disciplinas constituyen una opción actual y futura para solucionar problemas atingentes a pacientes pediátricos.

\section{Referencias}

1. Breuer C, Anthony T, Fong P. Potential tissue-engineering applications for neonatal surgery. Semin Perinatol. 2004;28:164-73.

2. Dunn JCY. Tissue engineering and regenerative science in pediatrics. Pediatr Res. 2008;63:459-60.

3. Grikscheit TC, Vacanti JP. The history and current status of tissue engineering: the future of pediatric surgery. $\mathrm{J}$ Pediatr Surg. 2002;37:277-88.

4. Saxena AK. Tissue engineering and regenerative medicine research perspectives for pediatric surgery. Ped
Surg Int. 2010;26:557-73.

5. Langer R, Vacanti JP. Tissue engineering. Science. 1993;260:920-26.

6. Langer R, Tirrell DA. Designing materials for biology and medicine. Nature 2004;428:487-92.

7. Barron V, Lyons E, Stenson-Cox C, McHugh PE, Pandit A. Bioreactors for cardiovascular cell and tissue growth: a review. Ann Biomed Eng. 2003;31:1017-30.

8. Dohmen PM, Lembcke A, Hotz H, Kivelitz D, Konertz WF. Ross operation with a tissue-engineered heart valve. Ann Thorac Surg. 2002;74:1438-42.

9. Cebotari S, Lichtenberg A, Tudorache I, Hilfiker A, Mertsching $\mathrm{H}$, Leyh $\mathrm{R}$, et al. Clinical application of tissue engineered human heart valves using autologous progenitor cells. Circulation 2006;114:I-132-7.

10. Matsumura G, Hibino N, Ikada Y, Kurosawa H, Shin'oka T. Successful application of tissue engineered vascular autografts: clinical experience. Biomaterials 2003; 24:2303-8.

11. Shin'oka T, Imai Y, Ikada Y. Transplantation of a tissue-engineered pulmonary artery. $\mathrm{N}$ Engl $\mathrm{J}$ Med. 2001;344:532-3.

12. Shin'oka T, Breuer C. Tissue-engineered blood vessels in pediatric cardiac surgery. Yale J Biol Med. 2008;81:161-6.

13. Glotzbach JP, Levi B, Wong VW, Longaker MT, Gurtner GC. The basic science of vascular biology: implications for practicing surgeon. Plast Reconstr Surg. 2010;126:1528-38.

14. Kunisaki SM, Freedman DA, Fauza DO. Fetal tracheal reconstruction with cartilaginous graft engineered from mesenchymal amniocytes. J Pediatr Surg. 2006;41:67582.

15. Hoganson DM, Pryor II HI, Vacanti JP. Tissue engineering and organ structure: a vascularized approach to liver and lung. Pediatr Res. 2008;63:520-6.

16. Nalayanda DD, Wang Q, Fulton WB, Wang T-H, Abdullah F. Engineering an artificial alveolar-capillary membrane: a novel continuously perfused model within microchannels'. J Pediatr Surg. 2010;45:45-51.

17. Fuchs JR, Terada S, Hannouche D, Ochoa ER, Vacanti JP, Fauza DO. Fetal tissue engineering: chest wall reconstruction. J Pediatr Surg. 2003;38:1188-93.

18. Fauza DO, Marler JJ, Koka R, Forse AR, Mayer JE, Vacanti JP. Fetal tissue engineering: diaphragmatic replacement. J Pediatr Surg. 2001;36:146-51.

19. Saxena AK, Baumgart H, Komman C, Ainoedhofer H, Soltysiak P, Kofler K, et al. Esophagus tissue engineering: in situ generation of rudimentary tubular vascularized esophageal conduit using the ovine model. J Pediatr Surg. 2010;45:859-64.

20. Rocha FG, Whang EE. Intestinal tissue engineering: from regenerative medicine to model systems. J Surg Res. 2004;120:320-5.

21. Hashish M, Raghavan S, Somara S, Gilmont RR, Miyasaka E, Bitar KN, et al. Surgical implantation of a 
bioengineered internal anal sphincter. J Pediatr Surg. 2010;45:52-8.

22. Fiegel HC, Kneser U, Kluth D, Metzger R, Till H, Rolle U. Development of hepatic tissue engineering. Ped Surg Int. 2009;25:667-73.

23. Kulig KM, Vacanti JP. Hepatic tissue engineering. Transpl Immunol. 2004;12:303-10.

24. Narushima M, Kobayashi N, Okitsu T, Tanaka Y, Li S-A, Chen Y, et al. A human $\beta$-cell line for transplantation therapy to control type 1 diabetes. Nat Biotechnol. 2005;23:1274-82.

25. Grikscheit TC, Sala FG, Ogilvie J, Bower KA, Ochoa ER, Alsberg E, et al. Tissue engineered spleen protects again overwhelming pneumococcal sepsis in a rodent model. J Surg Res. 2008;149:214-8.

26. Fauza DO, Fishman SJ, Mehegan K, Atala A. Videofetoscopically assisted fetal tissue engineering: bladder augmentation. J Pediatr Surg. 1998;33:7-12.

27. Atala A. Bioengineered tissues for urogenital repair in childrens. Pediatr Res. 2008;63:569-75.

28. Atala A, Kim W, Paige KT, Vacanti CA, Retik AB. Endoscopic treatment of vesicoureteral reflux with a chondrocyte-alginate suspension. J Urol. 1994;152:641-43.

29. Kershen RT, Yoo JJ, Moreland RB, Krane RJ, Atala A. Reconstitution of human corpus cavernosum smooth muscle in vitro and in vivo. Tissue Eng. 2002;8:515-24.

30. De Philippo RE, Bishop CE, Filho LF, Yoo JJ, Atala A. Tissue engineering a complete vagina replacement from a small biopsy of autologous tissue. Transplantation 2008;86:208-14.

31. Roessger A, Denk L, Minuth WW. Potential stem/progenitor cell cultures within polyester fleeces to regenerate renal tubules. Biomaterials 2009;30:3723-32.

32. Brittberg $\mathrm{M}$, Lindahl $\mathrm{A}$, Nilsson $\mathrm{A}$, Ohlsson $\mathrm{C}$, Isaksson $\mathrm{O}$, Peterson L. Treatment of deep cartilage defects in the knee with autologous chondrocyte transplantation. N Eng J Med. 1994;331:889-95.

33. Vacanti CA, Bonassar LJ, Vacanti MP, Shufflebarger J. Replacement of avulsed phalanx with tissue-engineered bone. N Eng J Med. 2001;344:1511-14.

34. Longaker MT. Regenerative medicine: a surgeon's perspective. J Pediatr Surg. 2010;45:11-8.

35. Böttcher-Haberzeth S, Biedermann T, Reichmann E. Tissue engineering of skin. Burns 2010;36:450-60.

36. Wong VW, Rustad KC, Longaker MT, Gurtner GC. Tissue engineering in plastic surgery: a review. Plast Reconstr Surg. 2010;126:858-68.

37. Hee Ko S, Nauta A, Wong V, Glotzbach J, Gurtner GC, Longaker MT. The role of stem cell in cutaneous wound healing: what do we really know? Plast Reconstr Surg. 2011;127 (Suppl.):10S-20S.

38. Cao Y, Vacanti JP, Paige K, Upton J, Vacanti CA. Transplantation of chondrocytes utilizing a polymercell construct to produce tissue-engineered cartilage in the shape of a human ear. Plast Reconstr Surg. 1997;100:297-302.

39. Panetta NJ, Gupta DM, Slater BJ, Kwan MD, Liu KJ, Longaker MT. Tissue engineering in cleft palate and other congenital malformations. Pediatr Res. 2008;63:545-51.

40. Pozzobon M, Ghionzoli M, De Coppi P. ES, iPS, MSC, and AFS cells. Stem cells exploitation for Pediatric Surgery: current research and perspective. Ped Surg Int. 2010;26:3-10. 